\title{
Un viaje lejos de la guerra: Una temporada en Venecia, de Wlodzimierz Odojewski
}

\author{
Rocío PeÑalta CATAlán \\ Departamento de Filología Románica, Filología Eslava y Lingüística General \\ Universidad Complutense de Madrid \\ rpenalta@ucm.es
}

\begin{abstract}
RESUMEN
Una temporada en Venecia es una novela corta del escritor polaco Wlodzimierz Odojewski (1930), publicada en 2000 y traducida al español en 2009. La novela narra las experiencias de Marek, un niño de diez años que sueña con viajar a Venecia, tal y como le habían prometido sus padres. La inminencia de la Segunda Guerra Mundial obliga a los adultos a cambiar de planes y trasladarse a la casa de campo familiar, donde permanecen refugiados, lejos de la ciudad. Marek, ajeno a lo que sucede a su alrededor, ve truncado su proyecto de viajar a la ciudad de los canales; sin embargo, una fuga de agua en el sótano de la casa, que queda completamente inundado, le permite recrear una Venecia en miniatura que, de escenario para los juegos infantiles, acaba convirtiéndose en una vía de escape para toda la familia en medio de la tensión de la guerra.
\end{abstract}

Palabras clave: Una temporada en Venecia, Wlodzimierz Odojewski, narrativa, Segunda Guerra Mundial.

\section{A travel away from the war: Season in Venice by Wlodzimierz Odojewski}

\begin{abstract}
Season in Venice is a short story by Polish writer Wlodzimierz Odojewski (1930), first published in 2000. The novel narrates the experiences of Marek, a ten years old boy who dreams with travel to Venice, as it has been promised by their parents. The impending Second World War forces them to change their plans and to move to a country house, where they remain protect far from the city. Marek's dream of travelling to Venice is truncated; however, a water spring in the cellar of the house let him to create a little Venice that will become the way of escape for all the family in the middle of the war.
\end{abstract}

Keywords: Season in Venice, Wlodzimierz Odojewski, narrative, Second World War.

Una temporada en Venecia es una novela corta -apenas tiene cien páginas- del escritor polaco Wlodzimierz Odojewski (Poznan, 1930), fue escrita originalmente en 1976, reescrita en 1999, publicada en 2000 (Koneczniak 2012), traducida al español 
en 2009 y editada en España por Editorial Minúscula. La obra ha sido adaptada al cine por el director Jan Jakub Kolski, y estrenada en 2010 con el título de Wenecja.

El argumento se puede resumir fácilmente; pero esta sencillez solo es apariencia. Tras una historia casi naíf, narrada en tercera persona pero filtrada por un punto de vista infantil, se oculta una reflexión mucho más profunda sobre las consecuencias de una guerra incomprensible.

La novela cuenta las experiencias de Marek, un niño de diez años que sueña con viajar a Venecia, tal y como le habían prometido sus padres. La inminencia de la Segunda Guerra Mundial obliga a los adultos a cambiar de planes y trasladarse a la casa de campo familiar, donde permanecen refugiados, lejos de la ciudad. Marek, ajeno a lo que sucede a su alrededor, ve truncado su proyecto de viajar a la ciudad de los canales; sin embargo, una fuga de agua en el sótano de la villa, que queda completamente inundado, le permite recrear una Venecia en miniatura que, de escenario para los juegos infantiles, acaba convirtiéndose en una vía de escape para toda la familia en medio de la tensión de la guerra.

Esta es una novela hecha de ausencias. Lleva el nombre de Venecia en su título, pero la ciudad de los canales no es más que una ensoñación de Marek, un recuerdo de familia ${ }^{1}$, un reflejo en las tranquilas aguas que inundan el sótano de una casa de campo. Esta historia se desarrolla durante la Segunda Guerra Mundial, y la guerra no es más que un rumor de fondo, una amenaza invisible, un obstáculo incomprensible para Marek que, sin embargo, frustra sus sueños de niño de nueve años.

Estamos en el verano de 1939.

Para Marek, que va a cumplir diez años y, según su madre, «e[s] casi un hombre» (Odojewski 2009: 13-14) ${ }^{2}$, la guerra es algo abstracto e intangible. No entiende lo que está sucediendo, es algo «de mayores» y que parece muy lejano; sin embargo, obliga a cambiar los planes de toda la familia: a su hermano mayor Wiktor se le ponen todo tipo de trabas para ir al campamento de verano de los boyscouts; su padre recibe «la orden de presentarse en veinticuatro horas en el lugar donde estaba acuartelado su regimiento» (14), y Marek, bueno, Marek ve aplazado sine die su tan deseado viaje a Venecia.

Esta perspectiva, la de Marek, el protagonista del relato, es la que adoptaremos. Lejos de aportar fechas y nombres, contemplaremos la guerra desde la mirada de un niño, con la perplejidad de quien ve cómo cambia su vida sin entender lo que está pasando; de quien queda al margen de las conversaciones de adultos en que se tratan cuestiones «importantes», en las que se comentan las últimas noticias y se muestra preocupación por la evolución de los acontecimientos.

Pero comencemos por el principio.

Cuando Marek, que había estado preparando con entusiasmo su viaje, leyendo «más de una decena de libros sobre Venecia, que le había prestado la tía Barbara, y

\footnotetext{
${ }^{1}$ Venecia ocupa un lugar privilegiado entre los destinos de viaje de la familia de Marek, como se explica al inicio de la novela.

${ }^{2}$ De ahora en adelante, cada vez que se cite esta edición de Una temporada en Venecia, solo se indicará el número de página del que se ha extraído el fragmento.
} 
[recortando] un montón de fotos de las revistas con las imágenes más curiosas [de la ciudad] para pegarlas en su álbum» (10), recibe la noticia de que probablemente tendrán que quedarse en casa y dejar el viaje para más adelante, «y a pesar de que la decisión no era definitiva y que él tampoco estuvo dispuesto a aceptarla, lo cierto es que empezó a sentir una angustia creciente [...]» (12). Finalmente, después de múltiples discusiones que Marek no alcanza a entender, su padre sugiere que madre e hijo viajen a P. - una ciudad no identificada, de la que el narrador solo nos facilita la inicial ${ }^{3}$ - para pasar el verano en el campo, en la villa de la tía Weronika.

Marek y su madre son los primeros en llegar a P., donde les espera la tía Weronika -la hermana mayor de su madre- solo acompañada del viejo Seweryn, el jardinero. Al percatarse de que son los únicos invitados, la «alegría [de Marek] se desvaneció de golpe» (22), pues no deseaba otra cosa que tener un compañero de juegos. Enseguida, Marek descubre la presencia de Frosia, la «asistenta externa» de la tía Weronika (27), y de Zuzia, una niña de su edad que resulta ser la nieta del vecino, el señor Filipowicz (34).

El verano transcurre lenta, pesadamente al principio; en el silencio resonante de la casa, en el huerto y el jardín donde solo se escucha el gorjeo de los pájaros y el zumbido de las abejas, y donde Marek juega en solitario; más tarde, la paz será rota por las reuniones y los juegos, por las voces de sus tías y su prima, a medida que los familiares vayan incorporándose progresivamente al retiro en P., y los acontecimientos se precipiten.

La siguiente en llegar fue la tía Barbara, que «había sido y sería siempre su tía preferida»; de manera que, para Marek, la «estancia en P. empezaba poco a poco a compensar la decepción que envolvía el viaje a Venecia» (36). Poco después, aparecen en casa de la tía Weronika la prima Karola, hija de la tía Klaudyna, acompañada de su institutriz, la señorita Lilian, «una checa que se hacía pasar por francesa» (45). «Y entonces, cuando nadie lo esperaba, apareció la abuela» (47).

A medida que avanza el verano, que la guerra pasa de ser una posibilidad a convertirse en un hecho, que la población es movilizada -incluso la propia madre de Marek es alistada, como miembro de la Cruz Blanca (48)-, más miembros de la familia llegan a P. «Pero fue con la llegada de Wiktor cuando los acontecimientos adquirieron importancia y empezaron a sucederse más deprisa, no antes» (51).

Esa misma noche, poco antes del amanecer, Wiktor llamó a la puerta de la villa de tía Weronika. Todos los habitantes de la casa se despertaron, si es que algún adulto dormía realmente; sea como fuere antes de la llamada reinaba el silencio y después la casa se llenó de pronto de gritos y llamadas. Wiktor estaba en el porche, gris de polvo y suciedad; su uniforme de explorador, que había estrenado poco antes, ahora colgaba de él hecho jirones, las botas estaban llenas de barro seco, igual que la mochila que descansaba a sus pies. Wiktor les contó que él y otros compañeros habían tenido que viajar por carreteras secundarias de Polesie, desde el campamento de la región de Vilna, que todos los caminos estaban atestados de refugiados y tropas, que si hubie-

\footnotetext{
${ }^{3}$ Según explica Grzegorz Koneczniak (2012: 149), se trata de Przemyśl, ciudad situada a orillas del río San.
} 
ran viajado en un tren o en un autobús habrían tardado incluso dos semanas, que era imposible describir lo que pasaba y, acto seguido, se quedó dormido en el sillón a mitad de una frase, sucio y con el uniforme roto. Las tías y la abuela tuvieron que llevarle a una de las habitaciones vecinas donde, por suerte, había una cama como en casi todas las habitaciones. Y fue entonces cuando él, Marek, y Karola, comprendieron que desde hacía tres o cuatro días había guerra. (51)

Antes de que su hermano llegase a P., Marek intuía que algo estaba pasando, reflexionaba sobre ello durante sus juegos solitarios y, a pesar de la monotonía con que se sucedían los días en el campo, sabía que ya nada sería igual después de ese verano:

Al caer la tarde empezó a llover, así que se sintió aún peor. Sabía que esa no iba a ser la última lluvia del verano, que luciría el sol, impenitentemente, que las noches serían igual de calurosas y sofocantes, noches que no concederían un respiro a la agotada tierra, y así hasta que, al final, llegaría un tiempo en el que ya nada sería como aquello que había conocido y amado, y ya nada sería igual. (29)

Pero esto, que solo era un vago presentimiento en el espíritu infantil de Marek, se convierte en una realidad con la llegada de Wiktor. A partir de ese momento, la guerra, que hasta entonces había sido algo intangible y desconocido para Marek, adquiere estatuto de realidad ${ }^{4}$ : «Así que ya no necesitaban más explicaciones, ya sabían que eso que habían conocido únicamente a través de los libros y relatos de los familiares, ahora estaba sucediendo de verdad» (53).

Aunque sabe lo que significa la guerra, Marek no entiende del todo lo que sucede. A veces son los mayores los que prefieren mantenerle al margen (48, 52, 61, 98); otras veces es él quien se resiste a preguntar, casi con un instinto de autoprotección del que no llega a ser del todo consciente: prefiere simular que no ha escuchado nada (21). Las dudas brotan en su interior, pero no llega a formular las preguntas que le abrirían los ojos al mundo real, a lo que sucede -cada vez menos- lejos de la villa de la tía Weronika. A medida que avanza el relato, asistimos a la maduración de Marek en distintos aspectos: desde el descubrimiento del sexo femenino (26-28, 3941) hasta la asunción de una realidad tan dura como es la tragedia que significa una guerra (66-71): «[...] había otra cosa además, algo que por aquel entonces aún no comprendía, algo que iba a entender mucho más tarde: que su niñez se alejaba de un modo irrevocable a algún lugar» (71).

La guerra recorre las páginas de la novela de principio a fin y, sin embargo, nunca llega a enturbiar del todo la vida en casa de la tía Weronika: contemplamos las caras preocupadas de los adultos (15), los llantos sin causa aparente (21), las reu-

4 «Odojewski presents the war from the perspective of a young boy, who [...] is unaware of his own place in it. Marek does not comprehend the reason for which his father and mother are separated from him and what the whole mobilisation is really about. He does not ascribe any significance to the military troops he discerns in the water meadows. It is only after the return of his older brother Wiktor [...] from the front, that Marek realises that the war has just begun» (Koneczniak 2012: 142). 
niones para escuchar las noticias en la radio $(13,35,57)$, las conversaciones más o menos disimuladas. Está presente incluso en los juegos de los niños:

Más tarde, detrás de los arbustos de frambueso que hay junto a la empalizada, donde crecen el saúco, el serbal y las moras, volvió a golpear con su palo las ortigas y las ramas secas con rabia y ahínco; la imagen de la hierba abatida como filas de soldados enemigos caídos en una batalla le provocó una extraña alegría. (28)

Vemos cómo un grupo de ulanos acampa «en el linde que separa la pradera de la rastrojera de avena, y se tumba[n] uno junto al otro bajo los almiares de heno, con sillas bajo las espaldas y las mantas dobladas en rulo debajo de la cabeza» (49) para pasar la noche; oímos las sirenas que anuncian los ataques aéreos; contemplamos los aviones que sobrevuelan el cielo de P., primero con cruces negras en las alas, luego lanzando octavillas ${ }^{5}$; escuchamos los disparos de la artillería antiaérea e, incluso, logramos ver las carreteras llenas de refugiados y heridos cuando los niños se escapan de casa, ocultos en el carro de Seweryn. A pesar de este escenario, la empalizada que rodea el jardín de la tía Weronika parece proveer una seguridad y una paz inconcebibles en un contexto como el de la ocupación de Polonia.

Aunque la imagen de la Segunda Guerra Mundial que nos presenta Odojewski está filtrada a través de la inocencia de Marek, a diferencia de lo que ocurre con otros relatos de la guerra protagonizados por niños, en los que se presenta a los menores como absolutamente inocentes e ignorantes de lo que sucede (Page 2011: $3,4)$, tanto Marek como Karola y Wiktor son testigos de la crueldad de la contienda, que deja imágenes imborrables en su recuerdo 6 .

${ }^{5}$ La ocupación de Polonia por el ejército nazi se inició el 1 de septiembre de 1939. Dieciséis días después, el 17 de septiembre, fueron las tropas soviéticas las que invadieron el territorio polaco: «No hubo más bombardeos en P. A decir verdad, de vez en cuando sobre el cielo aparecía algún que otro avión aislado con cruces negras en las alas pero luego se alejaba; desde algún lugar lejano respondía la artillería con sus pesados y tímidos disparos. Pronto aparecieron en la carretera más refugiados que venían del este que se dirigían al oeste aunque, quién sabe, quizá eran las mismas personas del otro día, porque tenían el mismo aspecto fatigado, estaban quemados por el sol, cubiertos por una capa de polvo, parecida al moho, eran seres de otro mundo, un mundo en el cual la meta no sería llegar a algún lugar preciso para poder descansar, dormir o incluso quedarse para siempre, sino desplazarse sin cesar, sin respiro, sin la posibilidad de pararse y reflexionar un momento sobre sus vidas. Ahora sencillamente huían de los bolcheviques» (72-73).

${ }^{6}$ Una cuestión que está ausente de la novela es el Holocausto. Aunque en la narración aparecen personajes judíos, como el dueño de la fábrica procesadora de fruta, a quien Seweryn vende las manzanas de la tía Weronika, o Naumek, el hijo del dueño de la papelería que toca el violín en la Venecia improvisada por los protagonistas del relato, no se nos dice nada sobre su situación o su destino. Por una parte, estamos al inicio de la guerra; por otra, Marek, a través de cuya percepción asistimos a los acontecimientos, apenas puede intuir lo que va a suceder. «In Season in Venice there is no explicit mention of the Final Solution, which led to the death of Naumek. In Odojewski's short story, the death of the Jewish boy is only presented in a multiple dream vision experienced by Marek, in which he discerns bomb craters filled with the bodies of dead people, and Naumek [...]. The dream that befalls Marek is the only element of the plot through which the question of the Holocaust is filtered» (Koneczniak 2012: 143-144). 
Odojewski's narrator, notwithstanding the realistic descriptions of WWII scenes, as perceived by Marek, does not seek to explain or rationalise them. [...] the reasons for the new circumstances with which the boy is faced remain beyond the cognitive scope of the young protagonist. At some point he comes to think of the tragic event he witnessed as being part of some «horrible dream». It is only years later that the boy will finally comprehend what led to the state in which at night he was not able to sleep and, during the day, he was dazed with exhaustion. At the time the only available explanation seems the very vaguely defined notion of warfare, the knowledge of which for Marek has so far been accessible in books, films and distant stories. (Koneczniak 2012: 142)

Y entonces, cuando lo peor de la guerra parecía a punto de alcanzarlos, sucede algo mágico, en palabras de Karola (55), o milagroso, como lo describirá más tarde Frosia (59): «en el sótano, en el lugar donde se almacenaban para el invierno botes de compota y muchas botellas de vino de fruta, apareció una fuente natural. Fue él, Marek, quien la descubrió [...]» (53). Poco a poco, el agua va subiendo de nivel, hasta inundar todas las estancias del sótano. «Al viejo Seweryn se le ocurrió que la tía Weronika debería convertir la casa en un balneario y, esa misma tarde, todos discutieron a fondo y muy seriamente sobre el asunto» (59-60). Este acontecimiento doméstico parece centrar la atención de todos, adultos incluidos, y vemos cómo la guerra comienza poco a poco a alejarse del primer plano de las preocupaciones de los personajes de la novela. En medio del fragor de la guerra, de las terribles noticias sobre el avance de las tropas, del trauma de Wiktor que ha visto cosas horribles durante su huida, del miedo de los niños, la tía Barbara tiene una fabulosa idea: «Tenemos agua debajo de la casa. Antes de organizar aquí el balneario, o lo que sea, convertiremos esos espacios en canales, hay trastos de sobra para construir casas y palacios, y junto a la escalera instalaremos el embarcadero. Además, después podríamos llamar a la pensión Venecia...» (77). Lo que empieza como un juego para tranquilizar a los niños, acaba convirtiéndose en el centro de interés de toda la familia:

[...] algunos de los muebles de los cuartos de servicio los sacaron al desván o a otras dependencias; en cambio, las mesas de la lavandería, del cuarto de planchar y de coser, se trasladaron al espacio principal del sótano que se encontraba justo debajo del vestíbulo de la casa donde estaba la mesa de ping-pong. Todos los objetos formaban sobre el agua una superficie considerable, parecida a una isla; desde esa isla, atravesando pequeñas mesas de tablas de planchar y baldas sacadas de las partes bajas de las estanterías inundadas, se podía llegar, sin mojarse los pies, hasta las ventanas y, a través de ellas, pasar directamente al jardín. Él, Marek, no utilizaba este recorrido fácil ya que justo al principio bajó de uno de los caballetes la tina de madera más grande que había en la lavandería, la puso sobre el agua y, utilizando como remo un cucharón de madera que servía para remover la ropa interior en la caldera de hervir, fue remando hasta la escalera, que era el puerto. Las puertas de todos los cuartos estaban abiertas de par en par, lo que permitió disponer de una extensa superficie de pasillos, canales y un embarcadero; junto a la escalera y al lado de este último, hecha con los tableros de dos viejas máquinas de coser marca Singer, apareció la plaza de San Marcos; más adelante se abría una perspectiva a las bahías, palacetes y calles en los espacios laterales del sótano, más pequeños y más grandes, donde los armarios y 
estanterías colocadas junto a la pared hacían de casas y de palacios; el agua ondeaba, chapoteaba; la luz que entraba por la ventana del jardín iluminaba el interior con un color dorado con destellos verdosos, se refractaba sobre la superficie, brillaba, centelleaba, también las paredes estaban inundadas de titileos fogosos y fríos y todo parecía ser exactamente igual que en la verdadera ciudad «sobre el agua», Venecia. Y es probable que se olvidaran entonces, brevemente, de la guerra. (79-80)

El propio Wiktor sale de su mutismo y se ofrece a comprar farolillos de colores con sus ahorros (81) y Naumek, el hijo del dueño de la papelería, les acompaña tocando su violín en esa ciudad acuática y mágica construida en el sótano de la villa:

Y cuando sus últimos tonos se apagaron (aunque su eco resonaba aún en las profundidades del sótano, transportado por el agua hasta los rincones más recónditos para retornar enseguida como una mariposa nocturna), todos permanecieron sentados con rostros pensativos, aunque sonrientes, y solo pasado un rato rompieron a aplaudir. Cuando sus aplausos se acallaron y Naumek dejó de inclinarse, se oyeron nuevas palmadas desde el exterior, era la tía Weronika que estaba en una de las ventanas; tenía las mejillas sonrosadas y le brillaban los ojos como a una niña pequeña.

La tía Weronika se unió a ellos en el sótano, [...] se sentó en un taburete que le cedió Seweryn, aceptó la copa de vino de grosella que este le había llenado y tras haberlo saboreado con cuidado, [...] contempló la copa a contraluz con ojos de experto y dijo: «Asombroso...», y a pesar de que nadie sabía exactamente a qué se refería la tía, asintieron con la cabeza diligentes pensando en la música de Naumek; dicho sea de paso, todo resultaba asombroso, las luces flotando y reflejándose en el agua y sus voces, susurros y risas, y la música, también las construcciones con muebles y otros utensilios que hacía tiempo que habían dejado de ser muebles y objetos para convertirse, en su imaginación, en algo totalmente diferente. Fue al cabo de los años cuando comprendió que la tía Weronika no tenía por qué referirse únicamente a la música de Naumek. (87-88)

En este universo femenino - este gineceo, como describe el propio narrador la casa de la tía Weronika (54)-, el lector, como Marek, avanza envuelto en la dulzura de las voces de las mujeres, del rumor de los crujientes vestidos de seda, de la suavidad de las melenas recién peinadas, del perfume de la fruta madura, ajeno a la violencia de la guerra.

Esta novelita es una oda a la imaginación; pero a «la imaginación no cómo forma de escape sino como definición de lo específicamente humano, aquello que nos diferencia de los animales en medio de la barbarie, en este caso, de la segunda guerra mundial» (Giménez 2009).

[...] la tía Weronika vació su copa y dijo: «La música, querido mío, representa en este caso la imaginación. La poesía también valdría. También las estrellas, y las puestas y salidas del sol que se suceden una detrás de otra, lo queramos o no... Podrían ser los eternos ciclos de invierno y verano, la caída de hojas de árboles en otoño y la germinación en primavera, da igual... Únicamente tenemos que imaginarnos que hay cosas duraderas e invariables, y cosas pasajeras. Independientemente de los vientos que soplen y las tempestades peligrosas que se desaten. Tienes que saber que las cosas 
duraderas pueden salvarte incluso en medio de una tormenta. La imaginación puede traer socorro en los momentos más aterradores...». (89-90)

\section{Bibliografía}

GIMÉNEZ, Diego (2009): «Una temporada en Venecia, de Wlodzimierz Odojewski». Revista de letras, 07/07/2009. En: http://revistadeletras.net/una-temporada-en-venecia-dewlodzimierz-odojewski/ [Consulta: 11/05/2016].

KoneCZNIAK, Grzegorz (2012): "Out-with, Venice, and Dislocation: Revisions of the Second World War in Boyne's The Boy in the Striped Pyjamas and Odojewski's 'Season in Venice'», en Dorota Guttfeld, Monika Linke y Agnieszka Sowińska (eds.), (Re)Visions of History in Language and Fiction, pp. 134-151. Cambridge: Cambridge Scholars Publishing.

ODOJEWSKI, Wlodzimierz (2009): Una temporada en Venecia. Traducción de Katarzyna Olszewska Sonnenberg. Barcelona: Minúscula.

PAGE, Sue (2011): «Vaseline on the Lens: Contemporary Representations of the Holocaust in Children's Literature» [en línea]. En: http://www.inter-disciplinary.net/ ati/Evil/Evil\%209/page\%20paper.pdf. [Consulta: 19/05/2016].

\section{Filmografía}

Kolski, Jan Jakub (dir.) (2010): Wenecja. Polonia: Akson Studio / ITI Cinema. 